\title{
Creep-Induced Structural Changes in Ni-Si-B Amorphous Alloy
}

\author{
A. Juríková, ${ }^{1, a}$ J. Miškuf, ${ }^{1, b}$ K. Csach, ${ }^{1, c}$ and V. Ocelík ${ }^{2, d}$ \\ ${ }^{1}$ Institute of Experimental Physics, Slovak Academy of Sciences, Kољice, Slovakia \\ ${ }^{2}$ Department of Applied Physics, Materials Science Centre and Netherlands Institute of Metals \\ Research, University of Groningen, Groningen, The Netherlands \\ a akasard@saske.sk, ${ }^{\mathrm{b}}$ miskuf@saske.sk, ${ }^{\mathrm{c}}$ csach@saske.sk, ${ }^{\mathrm{d}}$ v.ocelik@rug.nl \\ The influence of the stress annealing on the reversible structural relaxation of a $N i-\mathrm{Si}-\mathrm{B}$ \\ amorphous ribbon was studied. Creep-induced structural changes in the amorphous structure were \\ derived from anisothermal DSC and dilatometric experiments. It is demonstrated that considerable \\ enthalpy and specimen length variations associated with the reversible structural relaxation are \\ observed after previous creep at higher temperatures.
}

Keywords: structural relaxation, inelastic strain, Ni-based amorphous alloys.

Introduction. Metallic glasses represent a class of metallic materials with unique physical and mechanical properties. From a thermodynamic point of view they are unstable and annealing them at elevated temperatures leads to structural relaxation. Many papers dedicated to structural changes, which manifest themselves through changes in various physical properties, have been published up to now [1-4]. They show that besides irreversible structural relaxation accompanied by annealing-out and quenching-in effects below the glass transition temperature, there are reversible structural changes brought about by thermal, magnetic, or mechanical effects. Atomic disorder and defects of various levels also play an important role in magnetic properties of metallic glasses [5, 6].

Glassy alloys with a high Ni content were found to exhibit a glass transition before crystallization. The combination of high glass-forming ability and good mechanical and soft magnetic properties of the $\mathrm{Ni}$-based glassy alloys indicates their perspective applications [7]. The homogeneous deformation ability is influenced by the structure of amorphous alloys, namely by the amount and mobility of defects. Creep and creep recovery experiments can help understanding these phenomena [8]. For this purpose, creep-induced structural changes in the $\mathrm{Ni}-\mathrm{Si}-\mathrm{B}$ amorphous alloy were studied by means of differential scanning calorimetry (DSC) and thermomechanical analysis (TMA) methods. The aim of the present work is to find out how the creep applied at different temperatures influences the reversible structural relaxation of the Ni-rich amorphous alloy.

Experimental Details. An amorphous metallic ribbon of the nominal composition $\mathrm{Ni}_{77.5} \mathrm{Si}_{7.5} \mathrm{~B}_{15}($ at. \%) with a thickness of $18.8 \mu \mathrm{m}$ prepared at the Institute of Physics of the Slovak Academy of Sciences in Bratislava by rapid quenching of the melt on a rotating disc was used in experiments. The amorphous structure of the samples was checked by $\mathrm{X}$-ray diffraction. The crystallization temperature of the amorphous ribbon determined by differential scanning calorimetry for an as-quenched sample at the temperature of the first crystallization peak onset was $T_{x}=492^{\circ} \mathrm{C}$.

The specimens of $5 \mathrm{~mm}$ width were cut from as-received ribbon and initially heated up to a preannealing temperature of $380^{\circ} \mathrm{C}$ and kept for $30 \mathrm{~min}$ to eliminate further irreversible structural relaxation processes. After cooling down, they were annealed at temperatures of 300,325 , and $350^{\circ} \mathrm{C}$ for about 18 hours under an external tensile stress of $282 \mathrm{MPa}$. After finishing the stress-annealing, the samples were cooled down to room temperature and then unloaded. Some preannealed samples were not subjected to loading and were used as reference specimens. Heat treatments were performed in a tube furnace

(C) A. JURIKOVÁ, J. MIS̃KKUF, K. CSACH, V. OCELIK, 2008 
in nitrogen atmosphere. DSC measurements were carried out using a Perkin Elmer DSC 7 differential scanning calorimeter. The enthalpy changes were measured under linear heating with a constant heating rate of $20^{\circ} \mathrm{C} / \mathrm{min}$ for both the stress-annealed and the reference samples.

An additional type of experiment was carried out by means of a Setaram TMA 92 thermomechanical analyzer in the tension arrangement with an absolute resolution of 10 $\mathrm{nm}$ and temperature stability better than $0.2^{\circ} \mathrm{C}$. A flow of pure nitrogen was used to protect a sample. The same sample with an initial length of $15 \mathrm{~mm}$ underwent several thermal treatments. The initial structure was stabilized by two subsequent heatings to the temperature $400^{\circ} \mathrm{C}$ that lies below the glass transition temperature of this amorphous material. Such a thermally treated sample was considered as a reference one. After creep annealing and cooling down to room temperature, the length changes under linear heating with a rate of $10^{\circ} \mathrm{C} / \mathrm{min}$ were recorded. Creep annealing was performed at temperatures of 195,345 , and $370^{\circ} \mathrm{C}$ for 18 hours under the applied mechanical stress $100 \mathrm{MPa}$.

Results and Discussion. Typical DSC traces recorded for samples annealed for a long time under the applied stress and without it at a temperature of $325^{\circ} \mathrm{C}$ are shown in Fig. 1. The insert shows a DSC thermogram for the whole measured temperature range. The arrows marked $T_{g}$ and $T_{x}$ indicate the glass transition and crystallization onset temperatures, respectively. Only the part of the DSC thermogram in the temperature range up to the glass transition temperature was taken into account.



Fig. 1. DSC traces recorded for the samples annealed at $325^{\circ} \mathrm{C}$ under and without stress. The insert shows a DSC thermogram for the whole measured temperature range.

The DSC traces obtained for samples subjected to stress annealing and for the load-free annealed samples (reference ones) have a similar shape. This trend was observed for all the stress annealing temperatures. The DSC scans recorded for the stress-annealed samples were always found to lie below those for the reference samples. This means that the structure of the samples subjected to loading is more packed according to the directional structural relaxation model [9] that estimates the influence of the mechanical stress on the structural relaxation of the samples. The extent of this phenomenon increases with increasing annealing temperature.

Figure 2 shows the differences of measured DSC data between the samples annealed at indicated temperatures under and without stress. It can be seen that the difference is the larger, the higher the stress annealing temperature. However, the stress annealing at higher temperatures leads above all to a dramatic increase in the relative amount of lower 
activation energy processes. Defects with a lower activation energy are especially responsible for reversible structural relaxation [10, 11].

To estimate the influence of creep conditions on the structure relaxation processes, some additional thermomechanical experiments were carried out. A sample was subjected to annealing at different temperatures under an applied load of $100 \mathrm{MPa}$ for about 18 hours. This resulted in the total strains derived from dilatometric experiments as summarized in Table 1.

$\mathrm{T}$ a b 1 e 1

Total Creep-Induced and Recovered Strains Derived from Dilatometric Experiments

\begin{tabular}{|c|c|c|c|}
\hline \multirow{2}{*}{$\begin{array}{c}\text { Creep temperature } \\
{\left[{ }^{\circ} \mathrm{C}\right]}\end{array}$} & \multicolumn{2}{|c|}{ Creep strain } & Recovered strain \\
\cline { 2 - 3 } & {$[\mu \mathrm{m}]$} & {$[\%]$} & {$[\%]$} \\
\hline 195 & 4.67 & 0.03 & 0.02 \\
345 & 56.75 & 0.38 & 0.10 \\
370 & 108.15 & 0.72 & 0.08 \\
\hline
\end{tabular}

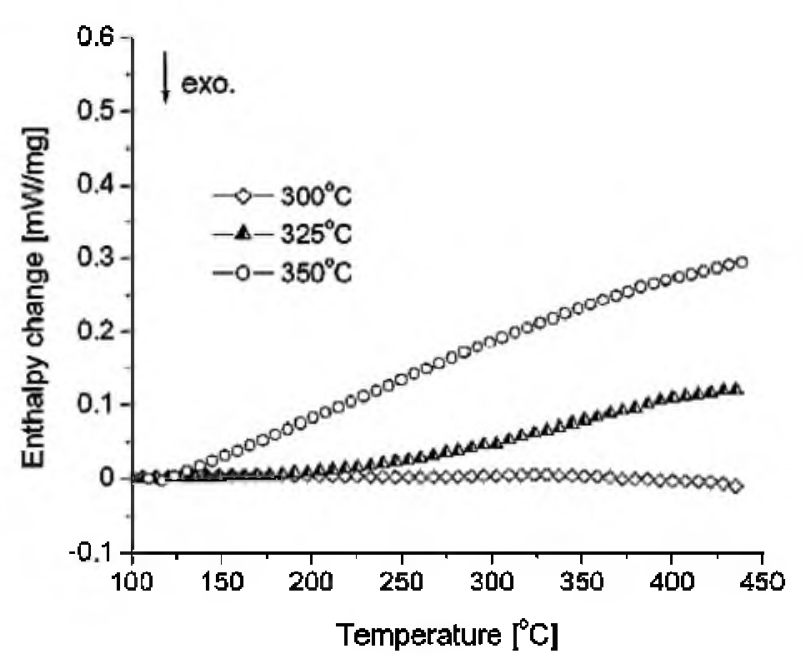

Fig. 2. The difference between the DSC traces recorded for the samples annealed at indicated temperatures under and without stress.

The higher temperature of creep annealing was applied, the higher total deformation was observed. Maximum permanent strain of $0.72 \%$ was introduced during creep annealing at a temperature of $370^{\circ} \mathrm{C}$.

After the creep annealing, thermal expansion curves were measured during linear heating. The thermal expansion was accompanied by relative contraction due to creep recovery processes. Nearly periodic alternations on dilatometric curves were caused by small non-linearity of the heating rate due to the temperature controller setting. The creep recovery contributions to the length changes under linear heating were estimated by subtracting the elongation curve values of the reference sample from those obtained after creep annealing at chosen temperatures.

Figure 3 shows the temperature dependence of creep recovery contributions to the length changes under linear heating after creep annealing realized at indicated temperatures. At higher temperatures, the amount of the recovered inelastic strain increases up to the maximum value of $0.1 \%$ in the case of annealing deformation defects introduced during creep applied at a temperature of $345^{\circ} \mathrm{C}$ (Table 1). Subsequent increasing of the creep 


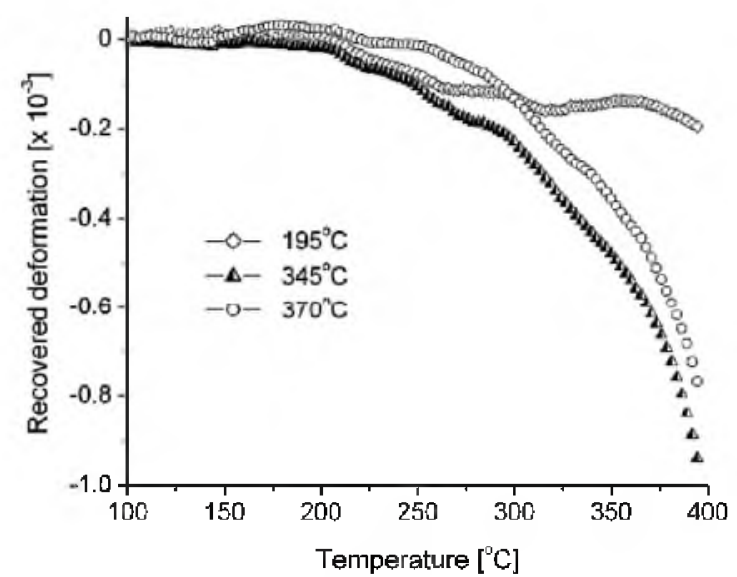

Fig. 3. The temperature dependence of the recovered inelastic strain measured after a long-time creep annealing at indicated temperatures.

annealing temperature has only a small influence on the measured value of the total creep recovery strain. A decreased sensitivity of the recovered strain value to the creep-induced one at higher temperatures can be caused by a relatively high heating rate used in the dilatometric experiments. At higher heating rates and given temperatures, the creep recovery processes caused by higher activation energy defects cannot be fully activated.

Conclusions. Accumulation of the creep strain of the Ni-Si-B amorphous ribbon is associated with structural changes observed as heat flow evolution under linear heating during the DSC experiment. An increase in the creep-induced strain leads to a larger amount of recovered inelastic strain, but only to a certain extent. At higher temperatures and higher values of the creep-induced strain, the relative amount of the recovered inelastic strain does not increase. VEGA.

Acknowledgment. This work was supported by the Slovak Grant Agency for Science -

1. A. Böhönyey, G. Huhn, L. F. Kiss, et al., Mat. Sci. Eng. A, Suppl., Proc. of the 9th Int. Conf. on Rapidly Quenched \& Metastable Materials (1997), p. 154.

2. K. Russew and F. Sommer, J. Non-Cryst. Solids, 319, 289 (2003).

3. K. Pękala, P. Jaśkiewicz, and D. Oleszak, Mat. Sci. Eng. A, Suppl., Proc. of the 9th Int. Conf. on Rapidly Quenched \& Metastable Materials (1997), p. 121

4. E. Jakubczyk and M. Jakubczyk, Czech. J. Phys., 54, D165 (2004).

5. A. Kalezić-Glišović, L. Novaković, A. Maričić, et al., Mat. Sci. Eng. B, 131, 45 (2006).

6. A. Lovas, K. Bản, J. Kováč, et al., Czech. J. Phys., 54, D89 (2004)

7. B. Shen and A. Inoue, Mater. Trans., 44, No. 7, 1425 (2003).

8. K. Csach, V. Ocelík, J. Miškuf, et al., IEEE Trans. Magn., 30, No. 2, 496 (1994).

9. V. A. Khonik, Phys. Stat. Sol. (a), 177, 173 (2000)

10. A. Juríková, K. Csach, J. Miškuf, et al., Centr. Eur. J. Physics, 5, No. 2, 177 (2007).

11. V. Ocelík, K. Csach, A. Kasardová, et al., Mat. Sci. Eng. A, 226-228, 851 (1997).

Received 28. 06. 2007 